\title{
EDITORIAL
}

\section{Inflammation and multiple myeloma: the Toll connection}

Leukemia (2006) 20, 937-938. doi:10.1038/sj.leu.2404229

Multiple myeloma (MM) is a B-cell malignancy critically dependent for survival and proliferation on signals coming from the microenvironment. ${ }^{1}$ These include most prominently the inflammatory cytokine IL- 6 as well as other cytokines and growth factors such as TNF $\alpha$ and IL-13. Two articles in the Journal, now report that MM express a vast repertoire of Toll-like receptors (TLR) and that TLR ligands potently promote the proliferation and survival of these malignant cells (Jego $G$ et al. and Bohnhorst $\mathrm{J}$ et al.). These results provide a fresh new perspective on the interaction between an inflammatory microenvironment and MM.

Human Toll-like receptors (TLR) include at least 10 type-I transmembrane proteins and form a larger superfamily with members of the IL-1 receptor family. ${ }^{2}$ TLR recognize diverse ligands ranging from microbial moieties (lipopeptide, lipopolysaccharides, nucleic acids) to, possibly, endogenous molecules. The ligand recognized by TLR10 remains elusive. Frequently, optimal recognition involves cooperation with a ligand recognizing molecules such as CD14, members of the scavenger receptor family or dectin-1., ${ }^{3,4}$ TLR are differentially expressed in leukocyte populations and B cells express substantial amounts of selected TLR, in particular TLR9 and 10. Activation by B-cell receptor engagement augments TLR levels in B cells, with high expression of TLR9 and TLR10 in activated and memory B cells (Figure 1). ${ }^{5,6}$

Engagement of TLR in B cells, for instance TLR9 by CpG oligonucleotides, stimulates proliferation, immunoglobulin release and chemokine production (Figure 1). 5,6 TLR-mediated activation of $B$ cells has been suggested to play a role in the generation of T cell-dependent antibody responses, ${ }^{7}$ in systemic autoimmunity $^{8}$ and in the maintenance of memory. ${ }^{9}$

The two articles in the Journal (Jego G et al. and Bohnhorst J et al.) now report that unlike normal plasma cells, MM express a wide and variable repertoire of TLR. Interestingly, while MM cells generally have high levels of a set of TLR (e.g. the nucleic acid recognizing TLR7, 8 and 9), TLR10, high on activated $B$ cells, ${ }^{6}$ is absent. TLR agonists such as CpG oligos induce MM proliferation and protect from dexamethasome-induced apoptosis. Strikingly, in both studies TLR agonists can substitute for IL-6 in the maintenance of MM cell lines. TLR-mediated induction of IL-6 plays an important role in the effect of TLR agonists on MM cells, but does not explain their action completely.

These reports raise several issues related to the biology and clinics of MM. TLR signalling is kept under check by multiple pathways of negative regulation including surface receptors (e.g. TIR8/SIGIRR ${ }^{10,11}$ ) and intracellular inhibitors. ${ }^{12,13}$ Are these pathways operative in MM? Do they account for observed dissociations between TLR expression and cell responsiveness in $\mathrm{MM}$ or for divergent effects of CpG oligos on B cell (apoptosis) $^{14,15}$ versus MM (protection from apoptosis)? Understanding the balance is key to therapeutic targeting of TLR in B-cell malignancy.

The actual in vivo relevance of TLR in MM is critically dependent on provision of appropriate ligands. Endogenous

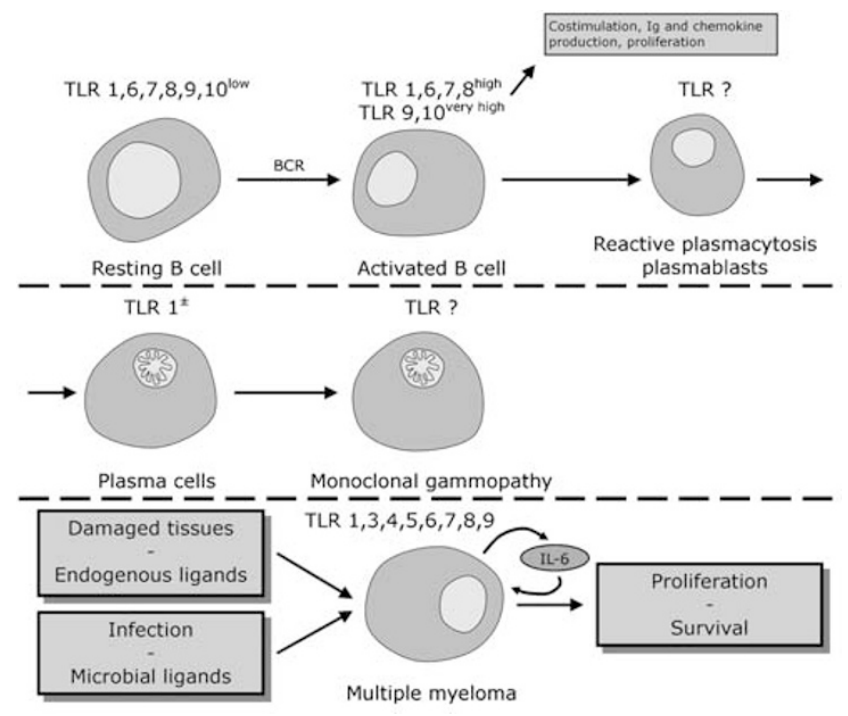

Figure 1 A schematic view of TLR in multiple myeloma. By way of comparison, normal B cells are shown. Question mark, unknown. Rp105 is not shown as it is expressed on all B cells and MM.

ligands (for a critical appraisal see ${ }^{8}$ ), such as nucleic acids from damaged tissues may provide an amplification loop in MM progression (Figure 1). Similarly, $M M$ is associated with immunosuppression and infection ${ }^{1}$ and a vicious circuit may ensue involving $\mathrm{MM}$, suppression of B cell responses, infection, promotion of MM. It will be important to ascertain whether reactive plasmacytosis, an expansion of plasma blasts and monoclonal gammopathy of undetermined significance express TLR and their function (Figure 1). Finally, the central question whether acquisition of a TLR repertoire actually contributes to the acquisition or maintenance of malignancy in $M M$ or is a mere epiphenomenon remains unanswered. At this stage, TLR expression in MM appears yet another molecular link between inflammatory reactions and malignancy. ${ }^{16-18}$

The results reported in the Journal should not be over interpreted to imply a general protumor function of TLR in the cancer microenvironment. Indeed, in a butylated hydroxytoluene-model of lung carcinogenesis, TLR4 dampens inflammation and cancer. ${ }^{19}$ Elucidation of the role of the TLR system will require an accurate dissection in different tumors.

\section{Acknowledgements}

This work was supported by Associazione Italiana per la Ricerca sul Cancro (AIRC), European Commission (project ATTACK n. 018914), Fondazione Cariplo (Project NOBEL), Ministero Istruzione Università e Ricerca (MIUR, Project FIRB).

A Mantovani ${ }^{1,2}$ and C Garlanda ${ }^{1}$

${ }^{1}$ Isituto Clinico Humanitas (ICH), Rozzano, Milan, Italy and

${ }^{2}$ Institute of General Pathology, Università degli Studi di 


\section{References}

1 Bataille R, Harousseau JL. Multiple myeloma. N Engl J Med 1997; 336: 1657-1664.

2 Kawai T, Akira S. Pathogen recognition with Toll-like receptors. Curr Opin Immunol 2005; 17: 338-344.

3 Jeannin P, Bottazzi B, Sironi M, Doni A, Rusnati M, Presta M et al. Complexity and complementarity of outer membrane protein $A$ recognition by cellular and humoral innate immunity receptors. Immunity 2005; 22: 551-560.

4 Mukhopadhyay S, Herre J, Brown GD, Gordon S. The potential for Toll-like receptors to collaborate with other innate immune receptors. Immunology 2004; 112: 521-530.

5 Bernasconi NL, Onai N, Lanzavecchia A. A role for Toll-like receptors in acquired immunity: up-regulation of TLR9 by BCR triggering in naive $B$ cells and constitutive expression in memory $B$ cells. Blood 2003; 101: 4500-4504.

6 Bourke E, Bosisio D, Golay J, Polentarutti N, Mantovani A. The toll-like receptor repertoire of human B lymphocytes: inducible and selective expression of TLR9 and TLR10 in normal and transformed cells. Blood 2003; 102: 956-963.

7 Pasare C, Medzhitov R. Control of B-cell responses by Toll-like receptors. Nature 2005; 438: 364-368.

8 Rifkin IR, Leadbetter EA, Busconi L, Viglianti G, Marshak-Rothstein A. Toll-like receptors, endogenous ligands, and systemic autoimmune disease. Immunol Rev 2005; 204: 27-42.

9 Bernasconi NL, Traggiai E, Lanzavecchia A. Maintenance of serological memory by polyclonal activation of human memory B cells. Science 2002; 298: 2199-2202.

10 Garlanda C, Riva F, Polentarutti N, Buracchi C, Sironi M, De Bortoli $\mathrm{M}$ et al. Intestinal inflammation in mice deficient in Tir8, an inhibitory member of the IL-1 receptor family. Proc Natl Acad Sci USA 2004; 101: 3522-3526.

11 Wald D, Qin J, Zhao Z, Qian Y, Naramura M, Tian L et al. SIGIRR, a negative regulator of Toll-like receptor-interleukin 1 receptor signaling. Nat Immunol 2003; 4: 920-927.

12 Liew FY, Xu D, Brint EK, O'Neill LA. Negative regulation of tolllike receptor-mediated immune responses. Nat Rev Immunol 2005; 5: 446-458.

13 Mantovani A, Locati M, Polentarutti N, Vecchi A, Garlanda C. Extracellular and intracellular decoys in the tuning of inflammatory cytokines and Toll-like receptors: the new entry TIR8/SIGIRR. Leukoc Biol 2004; 75: 738-742.

14 Jahrsdorfer B, Muhlenhoff L, Blackwell SE, Wagner M, Poeck H, Hartmann $\mathrm{E}$ et al. B-cell lymphomas differ in their responsiveness to CpG oligodeoxynucleotides. Clin Cancer Res 2005; 11: 1490-1499.

15 Jahrsdorfer B, Wooldridge JE, Blackwell SE, Taylor CM, Griffith TS, Link BK et al. Immunostimulatory oligodeoxynucleotides induce apoptosis of B cell chronic lymphocytic leukemia cells. J Leukoc Biol 2005; 77: 378-387.

16 Balkwill F, Charles KA, Mantovani A. Smoldering and polarized inflammation in the initiation and promotion of malignant disease. Cancer Cell 2005; 7: 211-217.

17 Balkwill F, Mantovani A. Inflammation and cancer: back to Virchow? Lancet 2001; 357: 539-545.

18 Coussens LM, Werb Z. Inflammation and cancer. Nature 2002; 420: $860-867$.

19 Bauer AK, Dixon D, DeGraff LM, Cho HY, Walker CR, Malkinson $\mathrm{AM}$ et al. Toll-like receptor 4 in butylated hydroxytoluene-induced mouse pulmonary inflammation and tumorigenesis. J Natl Cancer Inst 2005; 97: 1778-1781. 